\title{
Influence of type I collagen polymorphisms and risk of anterior cruciate ligament rupture in athletes: a case-control study
}

Jamila Alessandra Perini 1,2,3*, Lucas Rafael Lopes ${ }^{2,3}$, João Antonio Matheus Guimarães ${ }^{1}$, Rodrigo Araújo Goes ${ }^{4}$, Luiz Fernando Alves Pereira', Camili Gomes Pereira ${ }^{1,2}$, Marcelo Mandarino ${ }^{5}$, Alfredo Marques Villardi ${ }^{5}$, Eduardo Branco de Sousa ${ }^{5}$ and Victor Rodrigues Amaral Cossich ${ }^{1}$

\begin{abstract}
Background: Anterior cruciate ligament $(\mathrm{ACL})$ rupture is a common and severe knee injury in sports and occurs mostly due to noncontact injuries. There is an increasing amount of evidence associating ACL rupture to single nucleotide polymorphisms (SNPS), and SNPs in the collagen type I genes can change its expression and tissue mechanical features. This study aimed to investigate the association between SNPs in COL1A1 and COL1A2 with sports-related ACL tears.

Methods: A total of 338 athletes from multiple sports modalities were analyzed: 146 were diagnosed with ACL rupture or underwent an ACL reconstruction surgery and 192 have no musculoskeletal injuries. SNPs were genotyped using validated TaqMan assays. The association of the polymorphisms with ACL rupture was evaluated by a multivariable logistic regression model, using odds ratios (OR) and 95\% confidence intervals (Cl).

Results: The age, sport modality, and training location were associated with an increased risk of a non-contact ACL tear. COL1A2 SNPs (rs42524 CC and rs2621215 GG) were associated with an increased risk of non-contact ACL injury ( 6 and 4-fold, respectively). However, no significant differences were detected in the distribution of COL1A1 rs 1107946 and COL 1A2 rs412777 SNPs between cases and controls. There was a protective association with ACL rupture $(\mathrm{OR}=0.25 ; 95 \% \mathrm{Cl}=0.07-0.96)$ between COL1A1 rs 1107946 (GT or TT) and the wildtype genotypes of the three COL1A2 (rs412777, rs42524, rs2621215). COL1A2 rs42524 and rs2621215 SNPs were associated with non-contact ACL risk.
\end{abstract}

Conclusion: The combined analysis of COL1A1-COL1A2 genotypes suggests a gene-gene interaction in ACL rupture susceptibility.

Keywords: Collagen, ACL rupture, Polymorphisms, Athletes

*Correspondence: jamilaperini@yahoo.com.br; japerini@into.saude.gov.br ${ }^{3}$ Programa de Pós-graduação em Saúde Pública e Meio Ambiente, Escola Nacional de Saúde Pública, Fundação Oswaldo Cruz (Fiocruz), Rio de Janeiro, Brazil

Full list of author information is available at the end of the article

\section{Background}

The ligaments are mechanical restraints that help on the joint normal kinematics and stability $[1,2]$. In this context, the anterior cruciate ligament (ACL) is the main mechanical restrictor of excessive tibia anterior translation $[3,4]$ and prevents knee excessive external rotation and varus-valgus stresses, particularly under bodyweight bearing $[5,6]$. Hence, the ACL is crucial for the knee original author(s) and the source, provide a link to the Creative Commons licence, and indicate if changes were made. The images or other third party material in this article are included in the article's Creative Commons licence, unless indicated otherwise in a credit line to the material. If material is not included in the article's Creative Commons licence and your intended use is not permitted by statutory regulation or exceeds the permitted use, you will need to obtain permission directly from the copyright holder. To view a copy of this licence, visit http://creativecommons.org/licenses/by/4.0/. The Creative Commons Public Domain Dedication waiver (http://creativeco mmons.org/publicdomain/zero/1.0/) applies to the data made available in this article, unless otherwise stated in a credit line to the data. 
proper function, and its rupture leads to acute joint functional instability - anteroposterior and rotational laxity - functional symptoms, and other intra-articular structures damage [7]. Consequently, resulting in joint effusion, muscle weakness, altered movement pattern, and reduced functional performance [8].

ACL rupture is a very common and severe knee injury in sports and occur mostly due to noncontact injuries [9], being the most common mechanisms of a deceleration event together with a sudden change in direction with a planted and/or a non-compensated dynamic valgus during landing $[10,11]$. It makes the ACL tears of huge concern in sports involving jumping, pivoting, and cutting maneuvers [12, 13].

The treatment after an ACL rupture is mainly surgical, and the rehabilitation process is a time-consuming effort, which can endure up to 9-12 months for complete healing and return-to-sport [14, 15]. Nevertheless, even when treated properly there are odds for a second rupture, and development of concomitant and chronic degenerative articular injuries (e.g., meniscus tears, osteoarthritis) [16]. If it was not enough, surprisingly only $65 \%$ of soccer players return to participate at the same pre-injury level 3 years after the ACL tear [17]. Altogether those pieces of evidence highlight that an ACL tear is a social, economic, and professional burden for sports teams and the affected athlete [18]. Thus, a better understanding of the extrinsic - type and level of activity, playing surface, and equipment used - and intrinsic - sex, hormonal, anatomical, neuromuscular, and genetic contribution - risks factors is mandatory for designing target injury preventive interventions $[9,19,20]$.

There is an increasing amount of evidence that genetic sequence variants play an important role in ACL rupture occurrence [21,22] and single nucleotide polymorphisms (SNPs) in the collagen genes have already been associated with a genetic susceptibility for ACL rupture [20, 23-28]. What makes sense, since the ACL is a multi-fascicular structure - a built of dense and regular connective tissue mainly of collagen ( $75 \%$ of its dry weight) - predominantly of type I (up to $85 \%$ of ACL's collagen) [29, $30]$, which is believed it to be responsible for the ligament tensile strength $[6,29]$.

Type I collagen consists of two $\alpha 1$ and one $\alpha 2$ chains, encoded by the genes COL1A1 (chromosome 17q21) and COL1A2 (7q21.3), respectively. SNPs on those genes can change type I collagen expression and tissue mechanical features [31] and, consequently, affect human tissue development and repair [32, 33]. For example, the COL1A1 rs1107946 SNP located in the promoter region $(-1997 G>T)$ showed higher transcriptional activity, influencing gene expression regulation in the osteoblasts [34]. Also, SNPs in the COL1A2 gene at the coding or non-coding regions (rs412777, rs42524, and rs2621215) and their possible haplotypes can influence the type I collagen function [31] and, consequently, change the protein structure [32].

To the best of our knowledge, no studies evaluated the genetic combination of the COL1A1 and COL1A2 polymorphisms with susceptibility to ACL rupture. Thus, this study aimed to investigate the association between SNPs in both genes with sports-related ACL tears in athletes. The epidemiological, clinical, and athletic profiles were also explored to better understand the extrinsic and intrinsic ACL rupture risk factors in Brazilian athletes.

\section{Methods \\ Participants}

A total of 338 athletes between 18 and 45 years old from multiple sports modalities were prospectively selected for the present study. The subjects diagnosed with ACL rupture - only cases confirmed by clinical and magnetic resonance image - or who underwent an ACL reconstruction surgery previously were selected to compose the case group $(N=146)$. While the control group $(N=192)$ was composed of subjects without evidence of musculoskeletal injuries. Only subjects with complete orthopedic data and biological material collected were included in the present study. All subjects provided informed consent and the research was approved by the local Ethics Committee (\#2.455.630/2017). The study was conducted in accordance with the Helsinki Declaration.

\section{Experimental approach}

This was a case-control study. The volunteers were recruited between March 2018 and July 2019 at different sports training centers, sports competitions events, and the sports trauma outpatients service at our institution. First, the athletes answered the previously validated questionnaire to assess the general, training, and injuries information [35]. Follow a non-invasive sample from the oral mucosa was collected for genotyping analyses of collagen type I genes.

\section{Musculoskeletal injuries questionnaire}

Besides the data regarding musculoskeletal injuries' history, also was acquired clinical ACL tears-specific information as if the injury occurred during an official sports event, by contact or non-contact, report of post-training knee pain, ACL reconstruction surgery, injury recurrence, and time away from training due to the lesion, competitive practice (time and level), years of training, and weekly training hours. The data was collected with a printed version of the questionnaire "Musculoskeletal injuries report for Brazilian athletes" [35], immediately checked by the researcher who applied it with the athlete 
to clarify doubts and increase data reliance, and then the answers were transferred to a computational database and double-checked by different trained researchers.

\section{Polymorphism genotyping}

Athletes' genomic DNA was collected using a swab from the oral mucosa and isolated using an extraction kit (Qiagen, Hilden, Germany). Genotyping analyses of COL1A1 (rs1107946) and COL1A2 (rs412777, rs42524, rs2621215) SNPs were performed using TaqMan allelic discrimination assays (Table 1). For all polymorphisms, real-time polymerase chain reaction (PCR) was performed on a QuantStudio $^{\mathrm{TM}} 3$ Real-Time PCR System (Thermo Fisher Scientific, Waltham, MA USA). PCR amplification was performed in $8 \mu \mathrm{L}$ reactions with $1 \mu \mathrm{L}$ of template DNA

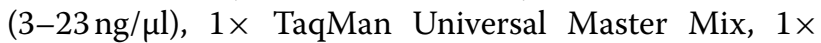
each primer and probe assay. Thermal cycling was initiated with a first denaturation step of $10 \mathrm{~min}$ at $95^{\circ} \mathrm{C}$, followed by 40 cycles of denaturation at $92^{\circ} \mathrm{C}$ for $15 \mathrm{~s}$ and annealing at $60^{\circ} \mathrm{C}$ for $1 \mathrm{~min}$. To assure genotyping quality, in each reaction two standardized positive controls of each polymorphism genotype were used, as previously described [36].

\section{Statistical analysis}

The data distribution was verified by the Shapiro-Wilk test. The case athletes were subdivided according to contact or non-contact ACL rupture. Continuous variables were reported as mean $\pm \mathrm{SD}$ and differences between all ACL rupture cases and controls groups were checked using the student's t-test. However, according to their distribution and clinical significance, for the analysis, continuous variables (age, years of training, and weekly training hours) were divided into quartiles. The nominal data were shown in proportions and differences between the two groups were evaluated using the Chi-squared ( $\chi 2)$ statistic test or Fischer exact test, when applicable. Deviations from Hardy-Weinberg equilibrium (HWE) were assessed by the goodness-of-fit $\mathrm{X} 2$ test. The distribution of alleles and genotypes of COL1A1 and COL1A2 polymorphisms were derived by gene counting and the difference of the frequencies between the groups were evaluated using the $\chi^{2}$ test or the Fisher's exact test, when appropriate. The haplotype patterns and linkage disequilibrium coefficients $\left(\mathrm{D}^{\prime}\right.$ : imbalance degree in module and $\mathrm{R}^{2}$ : correlation degree) were inferred using Haploview (https://haploview.software.informer.com/4.2/), as previously described [37]. The association analysis between epidemiological, sports, and training characteristics as much as of the polymorphisms with ACL rupture was estimated by the odds ratio (OR) with a $95 \%$ confidence interval $(95 \% \mathrm{CI})$. Multivariable logistic regression model by the stepwise method was performed to evaluate the possible associations and to set the final analysis model each variable was introduced considering its biological plausibility and univariate statistical significance [significance level - input: $P \leq 0.20$ and output: $P \leq 0.05]$. The statistically significant difference was set at $P \leq 0.05$. All analyses were performed using the Statistical Package for Social Sciences (SPSS Inc., Chicago, IL, USA, version 20.0). The sample size $(N=338)$ was appropriated to detect differences between case and control groups, assuming an odds ratio of 2.0 with a power of 0.8 and $5 \%$ type I error (Epi Info 7, version 7.1.3., https://www.cdc. gov/epiinfo/por/pt_pc.html).

\section{Results}

We observed a total of 146 ACL rupture cases, being 67 $(45.9 \%)$ due to a contact injury, 67 (45.9\%) were noncontact, and $12(8.2 \%)$ did not inform about the nature of the injury. In addition, 102 (70.8\%) underwent an ACL reconstruction surgery, while $42(29.2 \%)$ were waiting for the surgical procedure to be scheduled. Additional relevant ACL rupture-related information and its comparison between contact and non-contact injury subgroups are displayed in Table 2, and non-contact injuries were more likely ( $\sim 2.5$ times) to occur during training than contact injuries (Table 2).

The ACL rupture cases (both contact and noncontact subgroups) were significantly older than

Table 1 Characterization of COLIA1 and COL1A2 polymorphisms and probes for genotyping by TaqMan real-time PCR

\begin{tabular}{|c|c|c|c|c|c|}
\hline Gene & Identified SNP & Position & Location & TaqMan Assays & Probe $[S N P]$ \\
\hline COLIA1 & rs1107946 & $-1997 G>T$ & PR & C__ 7477171_10 & $\begin{array}{l}\text { CCTACTGTGGGTCAGTTCCAAGAGA [A/C] CCCCTCCCTAATAGGCGACAGGGG } \\
\mathrm{T}\end{array}$ \\
\hline COL1A2 & rs412777 & $19,276,090 A>C$ & Exon 25 & C__ 2545507_10 & $\begin{array}{l}\text { ACGGCAGGCCTGGCCCAATTGGCCC [A/C] } \\
\text { GCTGGAGCAAGAGGAGAGCCTGGCA }\end{array}$ \\
\hline COL1A2 & rs42524 & $19,277,392 G>C$ & Exon 28 & C__ 2258177_20 & $\begin{array}{l}\text { AGGTGGAAAAGGTGAACAGGGTCCC [C/G] CTGGTCCTCCAGGCTTCCAGG } \\
\text { TAAG }\end{array}$ \\
\hline COL1A2 & rs2621215 & $19,290,197 T>G$ & Intron 46 & C_16038824_10 & GTGAGGATTAAGGGAGATAGAAATA[G/T] ACATACAATAAAATCTCCTGGTAAC \\
\hline
\end{tabular}

$\mathrm{PR}$ is Promoter region 
Table 2 Clinical characteristics of the ACL injury-related information in the athletes

\begin{tabular}{|c|c|c|c|c|c|}
\hline \multirow[t]{2}{*}{ Variables } & $\begin{array}{l}\text { Injured Group } \\
(N=146)^{\mathrm{a}}\end{array}$ & $\begin{array}{l}\text { Contact ACL injury } \\
(N=67)\end{array}$ & $\begin{array}{l}\text { Non-contact ACL injury } \\
(N=67)\end{array}$ & $P$ - value ${ }^{\mathrm{b}}$ & OR (Cl 95\%) \\
\hline & \multicolumn{5}{|l|}{ N (\%) } \\
\hline \multicolumn{6}{|l|}{$A C L$ injury sporting event ${ }^{C}$} \\
\hline Competition & $72(54.5)$ & $42(64.6)$ & $30(45.5)$ & \multirow[t]{3}{*}{0.06} & $1^{d}$ \\
\hline Training & $47(35.7)$ & $17(26.2)$ & $30(45.5)$ & & $2.47(1.16-5.27)$ \\
\hline Competition and Training & $13(9.8)$ & $6(9.2)$ & $6(9.0)$ & & $1.40(0.41-4.76)$ \\
\hline \multicolumn{6}{|l|}{ Post-training knee pain } \\
\hline No & $69(47.3)$ & $29(43.3)$ & $32(47.8)$ & \multirow[t]{2}{*}{0.60} & $1^{d}$ \\
\hline Yes & $77(52.7)$ & $38(56.7)$ & $35(52.2)$ & & $0.83(0.42-1.65)$ \\
\hline \multicolumn{6}{|l|}{ Surgery number } \\
\hline 1 & $73(78.5)$ & $37(82.2)$ & $36(75.0)$ & \multirow[t]{2}{*}{0.40} & $1^{\mathrm{d}}$ \\
\hline$\geq 2$ & $20(21.5)$ & $8(17.8)$ & $12(25.0)$ & & $1.54(0.56-4.21)$ \\
\hline \multicolumn{6}{|l|}{$A C L$ injury recurrence ${ }^{f}$} \\
\hline No & $113(83.7)$ & $55(82.1)$ & $58(86.6)$ & \multirow[t]{2}{*}{0.48} & $1^{d}$ \\
\hline Yes & $22(16.3)$ & $12(17.9)$ & $9(13.4)$ & & $0.71(0.28-1.82)$ \\
\hline \multicolumn{6}{|l|}{ Time away from training } \\
\hline 1 to 3 months & $43(29.5)$ & $22(32.8)$ & $19(28.4)$ & \multirow[t]{4}{*}{0.87} & $1^{\mathrm{d}}$ \\
\hline 4 to 6 months & $37(25.3)$ & $17(25.4)$ & $17(25.4)$ & & $1.16(0.47-2.88)$ \\
\hline 7 to 9 months & $38(26.0)$ & $15(22.4)$ & $19(28.4)$ & & $1.47(0.59-3.66)$ \\
\hline$\geq 10$ months & $28(19.2)$ & $13(19.4)$ & $12(17.9)$ & & $1.07(0.39-2.89)$ \\
\hline \multicolumn{6}{|c|}{ OR is the Odds ratio; $\mathrm{Cl}$ is the confidence interval } \\
\hline \multicolumn{6}{|c|}{${ }^{a}$ Contact or non-contact ACL injury-related information was obtained from 134 athletes } \\
\hline \multicolumn{6}{|c|}{${ }^{\mathrm{b}} P$-value $\leq 0.05$ was obtained through the Chi-squared Test (Pearson $P$-value) to compare contact and non-contact $\mathrm{ACL}$ injuries } \\
\hline \multicolumn{6}{|c|}{ ' Information was obtained from 132 athletes ( 65 contact ACL injuries, 66 non-contact ACL injury and 1 without information about contact or non-contact ACL injury) } \\
\hline \multicolumn{6}{|l|}{${ }^{\mathrm{d}}$ Reference value } \\
\hline \multicolumn{6}{|c|}{${ }^{\mathrm{e}}$ Information was obtained from 93 athletes ( 45 contact $\mathrm{ACL}$ injury and 48 non-contact $\mathrm{ACL}$ ) } \\
\hline Information was obtained from & & & & & \\
\hline
\end{tabular}

controls $(27.2 \pm 6.1$ vs. $23.0 \pm 5.0$ years old, $P=0.002)$, with higher sports practice time $(12.4 \pm 6.7$ vs. $8.3 \pm 5.8$ years, $P=0.07$ ), and weekly training hours (15.5 \pm 9.8 vs. $12.3 \pm 6.7 \mathrm{~h}, P=0.01$ ) (Table 3 ). Table 3 describes the demographic, sport, and training characteristics of the studied athletes. In summary, all variables were analyzed to identify possible confounding variables of the true association between COL1A1 and COL1A2 SNPs and the ACL rupture. Initially, for the analysis of injured group, the variables age $(P<0.001)$, sex $(P=0.11)$, sport modality $(P=0.01)$, training location $(P=0.05)$, years of training $(P=0.03)$ were inserted in the logistic regression model. After the stepwise regression method, the variables age, sport modality, training location, and years of training remained in this model. On the other hand, for analysis of non-contact ACL rupture, only age, sport modality, and training location were considered confounding variables. The variables age, sport modality, training location, and years of training were associated with ACL rupture when considering injured group for the analysis. Likewise, the age, sport modality, and training location remained associated with only non-contact ACL rupture in athletes (Table 3 ).

The COL1A1 (rs1107946) and COL1A2 (rs412777, rs42524, rs2621215) SNPs were in Hardy-Weinberg equilibrium in the overall studied athletes and each group (case and control). Association analyses of the COL1A1 and COL1A2 SNPs with ACL rupture are shown in Table 4. After adjustment for confounding factors (age, sport modality, and training location) variant genotype $C C$ (rs42524), allele and genotypes variants $G$ and $G G$ (rs2621215) of the COL1A2 gene were associated with increased risk of non-contact ACL rupture. However, no significant differences were detected in allele or genotype distribution of all SNPs (COL1A1 rs1107946 and COL1A2 rs412777, rs42524, rs2621215) comparing control and injured group of the ACL tear (adjustment for age, sport modality, training location, and years of training).

Haplotypes of the COL1A2 gene were determined for all athletes. The results revealed that SNPs rs412777, rs42524, rs2621215 were in strong linkage disequilibrium, forming a single haploblock (Fig. 1A). Eight 
Table 3 Epidemiological, sport, and training characteristics of the athletes

\begin{tabular}{|c|c|c|c|c|c|c|c|}
\hline Variables & $\begin{array}{l}\text { Control } \\
(N=192) \\
N(\%)\end{array}$ & $\begin{array}{l}\text { Injured Group } \\
(N=146)\end{array}$ & $P$ - value ${ }^{a}$ & Adjusted OR (Cl 95\%) & $\begin{array}{l}\text { Non-contact } \\
\text { ACL }(N=67) \\
\mathrm{N}(\%)\end{array}$ & $P$-value ${ }^{a}$ & Adjusted OR (Cl 95\%) \\
\hline \multicolumn{8}{|l|}{ Age (years) ${ }^{d}$} \\
\hline 18 to 20 & $85(44.3)$ & $21(14.4)$ & $<0.001$ & $1^{\mathrm{e}}$ & $10(14.9)$ & $<0.001$ & $1^{e}$ \\
\hline 21 to 24 & $47(24.5)$ & $33(22.6)$ & & $3.64(1.80-7.38)$ & $10(14.9)$ & & $2.38(0.88-6.45)$ \\
\hline 25 to 29 & $35(18.2)$ & $44(30.1)$ & & $5.31(2.61-10.80)$ & $19(28.4)$ & & $5.69(2.29-14.12)$ \\
\hline 30 to 45 & $25(13.0)$ & $48(32.9)$ & & $7.37(3.45-15.75)$ & $28(41.8)$ & & $12.52(5.00-31.38)$ \\
\hline \multicolumn{8}{|l|}{ Sex } \\
\hline Female & $63(32.8)$ & $53(36.3)$ & 0.11 & $1^{e}$ & $20(29.9)$ & 0.87 & $1^{e}$ \\
\hline Male & $129(67.2)$ & $93(63.7)$ & & $0.64(0.38-1.10)$ & $47(70.1)$ & & $0.94(0.47-1.88)$ \\
\hline \multicolumn{8}{|l|}{ BMI $\left(\mathrm{Kg} / \mathrm{m}^{2}\right)$} \\
\hline$<25.0$ & $123(64.0)$ & $77(52.7)$ & 0.28 & $1^{e}$ & $37(55.2)$ & 0.99 & $1^{e}$ \\
\hline 25.0 a 29.9 & $56(29.2)$ & $54(37.0)$ & & $1.20(0.70-2.08)$ & $23(34.3)$ & & $1.00(0.50-2.03)$ \\
\hline$\geq 30$ & $13(6.8)$ & $15(10.3)$ & & $2.07(0.83-5.17)$ & $7(10.5)$ & & $1.28(0.37-4.42)$ \\
\hline \multicolumn{8}{|l|}{ Skin colour ${ }^{f}$} \\
\hline White & $72(37.9)$ & $52(37.1)$ & 0.76 & $1^{e}$ & $26(40.0)$ & 0.52 & $1^{e}$ \\
\hline Intermediate & $62(32.6)$ & $53(37.9)$ & & $1.12(0.62-2.01)$ & $21(32.3)$ & & $0.86(0.39-1.86)$ \\
\hline Black & $51(26.9)$ & $31(22.1)$ & & $0.83(0.42-1.61)$ & $15(23.1)$ & & $0.95(0.41-2.24)$ \\
\hline Others & $5(2.6)$ & $4(2.9)$ & & $1.57(0.35-7.01)$ & $3(4.6)$ & & $3.31(0.63-17.39)$ \\
\hline \multicolumn{8}{|l|}{ Sport modality } \\
\hline Rugby & $79(41.1)$ & $38(26.0)$ & 0.01 & $1^{e}$ & $15(22.4)$ & 0.03 & $1^{e}$ \\
\hline Soccer & $43(22.4)$ & $38(26.0)$ & & $1.56(0.73-3.32)$ & $22(32.8)$ & & $3.12(1.33-7.36)$ \\
\hline Combat & $20(10.4)$ & $29(19.9)$ & & $4.07(1.46-11.38)$ & $11(16.4)$ & & $5.57(1.45-21.48)$ \\
\hline Handball & $13(6.8)$ & 15 (10.3) & & $5.92(1.64-21.30)$ & $4(6.0)$ & & $4.40(0.85-22.86)$ \\
\hline Water polo & $21(11.0)$ & $6(4.1)$ & & $2.62(0.61-11.27)$ & $4(6.0)$ & & $7.16(1.14-45.09)$ \\
\hline Others & $16(8.3)$ & $20(13.7)$ & & $6.57(1.98-21.31)$ & $11(16.4)$ & & $10.22(2.08-50.24)$ \\
\hline \multicolumn{8}{|c|}{ Training location } \\
\hline Grass & $121(63.0)$ & $84(57.5)$ & 0.005 & $1^{e}$ & $41(61.2)$ & 0.01 & $1^{e}$ \\
\hline Sports court & $13(6.8)$ & $15(10.3)$ & & $0.46(0.11-1.93)$ & $6(8.9)$ & & $0.07(0.01-0.78)$ \\
\hline Mat & $20(10.4)$ & 29 (19.9) & & $0.60(0.25-1.42)$ & $11(16.4)$ & & $0.28(0.08-1.00)$ \\
\hline Pool & $24(12.6)$ & $7(4.8)$ & & $0.09(0.02-0.42)$ & $5(7.5)$ & & $0.04(0.01-0.42)$ \\
\hline Beach & $7(3.6)$ & $7(4.8)$ & & $0.30(0.07-1.34)$ & $2(3.0)$ & & $0.05(0.01-0.60)$ \\
\hline Others & $7(3.6)$ & $4(2.7)$ & & $0.04(0.01-0.36)$ & $2(3.0)$ & & $0.01(0.01-0.14)$ \\
\hline \multicolumn{8}{|c|}{ Years of training $^{d}$} \\
\hline$\leq 5$ & $69(35.9)$ & $24(16.4)$ & 0.03 & $1^{e}$ & $11(16.5)$ & 0.17 & $1^{e}$ \\
\hline 6 to 10 & $62(32.3)$ & $39(26.7)$ & & $1.81(0.93-3.54)$ & $21(31.3)$ & & $2.25(0.91-5.57)$ \\
\hline 11 to 15 & $41(21.4)$ & $42(28.8)$ & & $2.51(1.24-5.06)$ & $14(20.9)$ & & $1.72(0.64-4.62)$ \\
\hline$>15$ & $20(10.4)$ & $41(28.1)$ & & $2.65(1.20-3.54)$ & $21(31.3)$ & & $2.79(1.02-7.64)$ \\
\hline \multicolumn{8}{|c|}{ Weekly training hours ${ }^{d}$} \\
\hline$\leq 8$ & $63(32.8)$ & $32(21.9)$ & 0.40 & $1^{e}$ & $15(22.4)$ & 0.29 & $1^{e}$ \\
\hline 9 to 12 & $58(30.2)$ & $37(25.3)$ & & $0.94(0.47-1.91)$ & $16(23.9)$ & & $1.08(0.43-2.67)$ \\
\hline 13 to 18 & $38(19.8)$ & $36(24.7)$ & & $1.45(0.71-2.96)$ & $15(22.4)$ & & $1.51(0.60-3.83)$ \\
\hline$>18$ & $33(17.2)$ & $41(28.1)$ & & $1.57(0.74-3.36)$ & $21(31.3)$ & & $2.26(0.89-5.73)$ \\
\hline
\end{tabular}

$\mathrm{OR}$ is the Odds ratio; $\mathrm{Cl}$ is the confidence interval

a $P$-value $\leq 0.05$ was obtained through the Chi-squared Test (Pearson $P$-value)

${ }^{b} \mathrm{OR}$ adjusted by age, sport modality, training location and years of training

' $O R$ adjusted by age, sport modality, and training location

${ }^{d}$ Values are categorized according to the quartile distribution of the total study population

e Reference value

${ }^{f}$ Information was obtained from 230 athletes (control $=190$, injured group $=140$, non-contact $A C L=65$ ) 
Table 4 Association analyses of the COL 1A1 and COL1A2 polymorphisms with ACL rupture

\begin{tabular}{|c|c|c|c|c|c|c|c|}
\hline \multirow[t]{2}{*}{ SNPs } & Control $(N=192)$ & $\begin{array}{l}\text { Injured Group } \\
(N=146)\end{array}$ & $P-$ value $^{\mathrm{a}}$ & Adjusted OR (Cl 95\%) & $\begin{array}{l}\text { Non-contact } \\
A C L(N=67)\end{array}$ & $P$-value ${ }^{a}$ & Adjusted OR (Cl 95\%) \\
\hline & \multicolumn{4}{|l|}{$N(\%)$} & \multicolumn{3}{|l|}{ N (\%) } \\
\hline \multicolumn{8}{|l|}{ COLIA1 } \\
\hline \multicolumn{8}{|c|}{ rs1107946 } \\
\hline GG & $110(57.9)$ & $92(63.4)$ & 0.71 & $1^{d}$ & $45(67.2)$ & 0.69 & $1^{d}$ \\
\hline GT & $65(34.2)$ & $43(29.7)$ & & $0.82(0.47-1.40)$ & $17(25.3)$ & & $0.77(0.37-1.57)$ \\
\hline TT & $15(7.9)$ & $10(6.9)$ & & $1.10(0.43-2.81)$ & $5(7.5)$ & & $1.22(0.37-3.94)$ \\
\hline G & $285(75.0)$ & $227(78.3)$ & 0.96 & $1^{d}$ & $107(79.9)$ & 0.93 & $1^{d}$ \\
\hline$T$ & $95(25.0)$ & $63(21.7)$ & & $0.99(0.65-1.50)$ & $27(20.1)$ & & $1.02(0.59-1.78)$ \\
\hline \multicolumn{8}{|l|}{ COL1A2 } \\
\hline \multicolumn{8}{|c|}{ rs $412777^{f}$} \\
\hline$A A$ & $77(41.0)$ & $67(46.2)$ & 0.33 & $1^{d}$ & $30(44.8)$ & 0.40 & $1^{d}$ \\
\hline$A C$ & $87(46.3)$ & $62(42.8)$ & & $0.81(0.48-1.36)$ & $31(46.3)$ & & $1.03(0.53-1.99)$ \\
\hline CC & $24(12.8)$ & $16(11.0)$ & & $0.55(0.25-1.24)$ & $6(8.9)$ & & $0.49(0.17-1.47)$ \\
\hline$A$ & $241(64.1)$ & $196(67.6)$ & 0.16 & $1^{d}$ & $91(67.9)$ & 0.34 & $1^{d}$ \\
\hline$C$ & $135(35.9)$ & $94(32.4)$ & & $0.77(0.53-1.11)$ & $43(32.1)$ & & $0.80(0.50-1.28)$ \\
\hline \multicolumn{8}{|c|}{ rs425249 } \\
\hline GG & $128(67.0)$ & $88(60.7)$ & 0.26 & $1^{d}$ & $41(61.2)$ & 0.09 & $1^{d}$ \\
\hline GC & $59(30.9)$ & $48(33.1)$ & & $1.22(0.73-2.04)$ & $21(31.3)$ & & $1.19(0.60-2.35)$ \\
\hline CC & $4(2.1)$ & $9(6.2)$ & & $2.85(0.76-10.75)$ & $5(7.5)$ & & $5.73(1.22-26.95)$ \\
\hline G & $315(82.5)$ & $224(77.2)$ & 0.17 & $1^{d}$ & $103(76.9)$ & 0.10 & $1^{d}$ \\
\hline$C$ & $67(17.5)$ & $66(22.8)$ & & $1.35(0.88-2.06)$ & $31(23.1)$ & & $1.57(0.92-2.69)$ \\
\hline \multicolumn{8}{|c|}{$\operatorname{rs} 2621215^{f}$} \\
\hline TT & $116(61.7)$ & 78 (53.8) & 0.18 & $1^{d}$ & $35(52.2)$ & 0.06 & $1^{d}$ \\
\hline$T G$ & $64(34.0)$ & $56(38.6)$ & & $1.38(0.83-2.30)$ & $25(37.3)$ & & $1.32(0.67-2.59)$ \\
\hline$G G$ & $8(4.3)$ & $11(7.6)$ & & $2.36(0.83-6.68)$ & $7(10.4)$ & & $4.29(1.26-14.61)$ \\
\hline$T$ & $296(78.7)$ & $212(73.1)$ & 0.08 & $1^{d}$ & 95 (70.9) & 0.04 & $1^{d}$ \\
\hline$G$ & $80(21.3)$ & 78 (26.9) & & $1.42(0.96-2.13)$ & $39(29.1)$ & & $1.69(1.02-2.81)$ \\
\hline
\end{tabular}

$\mathrm{OR}$ is the Odds ratio; $\mathrm{Cl}$ is the confidence interval

${ }^{\text {a }} P$-value $\leq 0.05$ was obtained through the Chi-squared Test (Pearson $P$-value)

${ }^{b}$ OR adjusted by age, sport modality, training location and years of training

' $O R$ adjusted by age, sport modality, and training location

${ }^{\mathrm{d}}$ Reference value

${ }^{\text {e }}$ Successful genotyping was 335 samples

${ }^{\mathrm{f}}$ Successful genotyping was 333 samples

${ }^{9}$ Successful genotyping was 336 samples

haplotypes could be inferred and $A G T$ haplotype was considered wildtype/reference haplotype due to present the highest frequency in the study population $(N=320$, 47.3\%). However, after multivariate analysis, no significant differences were detected in haplotype frequencies between controls and injured group of ACL rupture, neither between controls, nor non-contact injury (Fig. 1B).

On the other hand, a combined analysis of the four studied COL1A1 and COL1A2 SNPs was performed to investigate whether the presence of more than one SNP would increase the risk of developing the ACL rupture (Table 5). After adjustment for age, sport modality, training location, and years of training, combined variant genotype COL1A1 GT or TT (rs1107946) and the wildtype genotypes of the three COL1A2 (rs412777 - AA, rs42524 - GG, rs2621215 - TT) SNPs were negatively associated with ACL rupture compared with the reference wild-type genotypes COL1A1 (rs1107946 - GG) and COL1A2 (rs412777 - AA, rs42524 - GG, rs2621215 - TT).

\section{Discussion}

The two main findings of this study were that COL1A2 SNPs (rs42524 and rs2621215) increased the non-contact ACL tear risk and the rs1107946 COL1A1 SNP was 

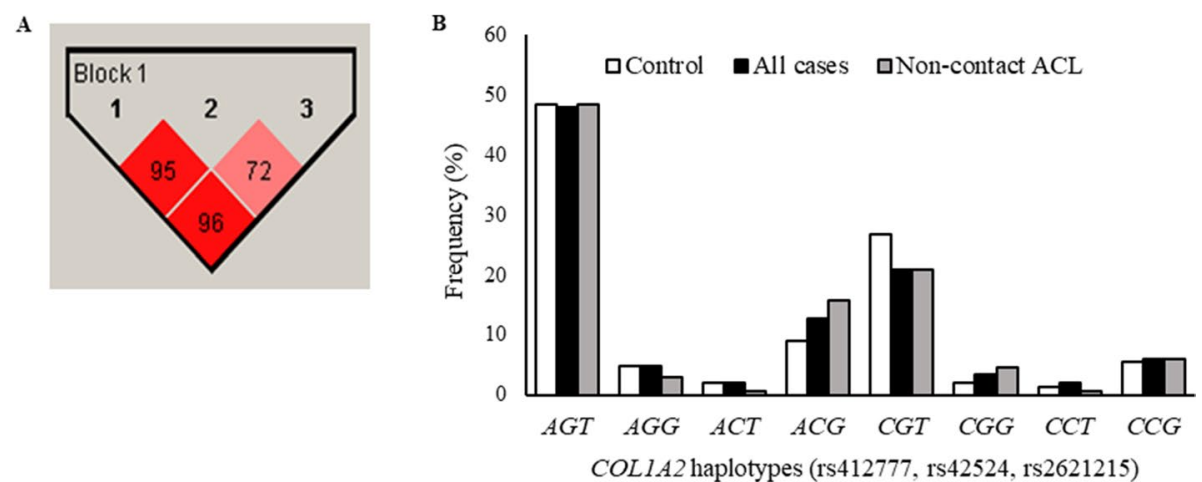

Fig. 1 Haplotype analysis for COL1A2 (rs412777, rs42524, rs2621215) SNPs in Brazilian athletes. A. Number in boxes indicates decimal places of D'. B. Haplotype distributions between injured group and non-contact ACL injury compared to control group

associated with ACL tear only when the three COL1A2 SNPs (rs412777, rs4252, and rs2621215) were wildtype. These results are in line with the previous studies suggesting that genetic contributions should be considered as an intrinsic and non-modifiable risk factor for ACL rupture susceptibility [9], and that polymorphisms in collagen genes may contribute to the development of this injury in both sexes $[25,27,28]$.

It is currently accepted that ACL tears have multifactorial etiology, represent $\sim 50-60 \%$ of knee injuries [38] and usually $(70-84 \%)$ occur through low-energy non-contact events $[39,40]$. In the present study, age, sport modality, training location, and time of practice were associated with an ACL tear in general. However, in the non-contact ACL tear subgroup, only age, sport modality, and training location remained associated with the injury. Those were already well-described risk factors associated with ACL rupture [40-44]. Moreover, our results reinforce the higher risks to ACL rupture according to sport modality and training location - for example, soccer (3-fold) for soccer players and grass [45].

We observed that the COL1A2 rs2621215 GG genotype was associated with non-contact ACL rupture risk (4-fold). This SNP is in intron 46 and can interact with other functional polymorphisms and affect the removal of these gene introns [46]. Thus, the presence of the variant allele $G$ rs 2621215 could produce more rigid collagen and increase the risk of ACL rupture susceptibility. Also, COL1A2 rs42524 $G>C$, located in exon 28, increased the risk of non-contact ACL ( 6-fold). This coding SNP causes alanine to proline substitution at amino acid residue 459 (Ala459Pro) in the Y-position of the Gly-X-Y

Table 5 Combined analysis of the COL1A1 and COL1A2 polymorphisms and the risk of developing ACL injury

\begin{tabular}{|c|c|c|c|c|c|c|c|}
\hline COL $1 A 1$ and COL1A2 & Control $(N=192)$ & $\begin{array}{l}\text { Injured } \\
\text { Group } \\
(N=146)\end{array}$ & $P$-value ${ }^{a}$ & Adjusted OR (Cl 95\%) & $\begin{array}{l}\text { Non-contact } \\
\mathrm{ACL}(N=67)\end{array}$ & $P-$ value $^{\mathrm{a}}$ & Adjusted OR (Cl 95\%) \\
\hline $\begin{array}{l}\text { rs } 1107946+(r s 412777 \\
/ r s 4252 / r s 2621215)^{e}\end{array}$ & N (\%) & & & & N (\%) & & \\
\hline$W T / 3 W T$ & $13(7.0)$ & $16(11.0)$ & 0.32 & $1^{d}$ & $8(11.9)$ & 0.34 & $1^{d}$ \\
\hline WT / IVAR & $58(31.2)$ & $37(25.5)$ & & $0.39(0.15-1.02)$ & $16(23.9)$ & & $0.43(0.13-1.42)$ \\
\hline WT / 2VAR & $24(12.9)$ & $26(17.9)$ & & $0.58(0.21-1.65)$ & $16(23.9)$ & & $0.91(0.26-3.17)$ \\
\hline WT/3VAR & $12(6.4)$ & $13(9.0)$ & & $0.65(0.20-2.15)$ & $5(7.5)$ & & $0.62(0.13-2.94)$ \\
\hline$V A R / 3 W T$ & $13(7.0)$ & $8(5.5)$ & & $0.25(0.07-0.96)$ & $4(6.0)$ & & $0.33(0.06-1.74)$ \\
\hline VAR/IVAR & $38(20.4)$ & $20(13.8)$ & & $0.41(0.14-1.15)$ & $7(10.4)$ & & $0.35(0.09-1.40)$ \\
\hline VAR/2VAR & $20(10.8)$ & $21(14.5)$ & & $0.79(0.26-2.35)$ & $8(11.9)$ & & $0.96(0.24-3.90)$ \\
\hline VAR/3VAR & $8(4.3)$ & $4(2.8)$ & & $0.45(0.10-2.13)$ & $3(4.5)$ & & $1.46(0.25-8.46)$ \\
\hline
\end{tabular}

$\mathrm{OR}$ is the Odds ratio; $\mathrm{Cl}$ is the confidence interval

a $P$-value $\leq 0.05$ was obtained through the Chi-squared Test (Pearson $P$-value)

${ }^{b}$ OR adjusted by age, sport modality, training location and years of training

' OR adjusted by age, sport modality, and training location

${ }^{\mathrm{d}}$ Reference value

e Successful combined genotypes were 331 samples 
repeat of the collagen I $\alpha 2$ helical region [46, 47], and the change in protein conformation affects collagen type I stiffness, which the Pro-459 variant amino acid is more rigid than that the Ala-459 [46]. Theoretically, more rigid collagen might produce stiffer (or less compliant) ACL, consequently reducing the tissue capacity to dissipate mechanical energy and increasing the chance of failure with reduced external forces [48].

Interestingly, the combined variant genotype COL1A1 rs1107946 with wildtype genotypes of the three COL1A2 (rs412777, rs42524, rs2621215) SNPs produced a protective factor to the ACL tear. The rs1107946 located on the promoter region of the COL1A1 gene $(-1997 G>T)$ and the presence of variant allele $G$ has a higher transcriptional activity than the wild-type allele $T$ [25, 34]. Also, this finding agrees with Ficek et al., who did not observe any association of the COL1A1 rs1107946 with ACL rupture, except when it was combined with the COL1A1 rs1800012 SNP [25]. Sivertsen et al. analyzed six collagen genes polymorphisms (COL1A1, COL3A1, COL5A1, and COL12A1), including COL1A1 rs1107946, and did not observe an association between ACL rupture risk and selected polymorphisms in female elite athletes from Norway and Finland. However, no combined genotype analysis was conducted [49]. Here, the cumulative effect of the COL1A1 and COL1A2 SNPs suggested a gene-gene interaction that might change the collagen type $1 \alpha 1 / \alpha 2$ chains ratio, thus predisposing the ACL rupture.

Hence, genetic investigations may help in the understanding of non-contact ACL ruptures [40]. This was the first study investigating a genetic combination of the COL1A1 and COL1A2 polymorphisms to the susceptibility to a non-contact ACL tear in athletes. Besides the several strong points, like adequate sample size and all injured subjects were diagnosed confirmed by a gold standard medical image exam or underwent an ACL surgical reconstruction, some limitations should be kept in mind. There is always the risk of recall bias in selfreported questionaries, twelve subjects did not remember the injury nature (contact or non-contact) and were excluded from the subgroup analysis (Table 2), and genotyping failure of some samples. However, we believe those limitations did not affect the statistical outcomes.

Investigating the link between ACL rupture and genetic variants is an important subject to a better elucidation of injury etiology and risk factors. The present results can be used to build a database from different populations to identify the impacts of genetics SNPs on ACL rupture risk [50]. Therefore, the knowledge regarding possible individual predisposing factors is essential to understand the molecular mechanism of ACL rupture and improve the disease prognosis by screening and prevention protocols. Due to the loss of physical performance, sports ability of their subjects, and high treatment costs, the genetic information can assist in ACL tear susceptibility identification, as contributing to individualized training and surveillance for monitoring the at-risk individuals. However, caution should be considered when generalization those results to other populations, and further studies should be carried on this topic.

\section{Conclusion}

In summary, COL1A2 rs42524 and rs2621215 SNPs were associated with non-contact ACL risk, which represents an advance in understanding the etiology of disease. The combined analysis of COL1A1-COL1A2 genotypes suggests a gene-gene interaction in ACL rupture susceptibility. These findings suggest that polymorphism screening could identify athletes with a higher risk of non-contact ACL rupture, which could benefit from specific training and surveillance protocols to prevent lesions.

\section{Abbreviations \\ ACL: Anterior cruciate ligament; 95\% Cl: 95\% Confidence interval; X2: Chi- square; BMI: Body mass index; COL1A1: Collagen type I alpha 1 chain; COL1A1: Collagen type I alpha 2 chain; HWE: Hardy-Weinberg equilibrium; OR: Odds ratio; PCR: Polymerase chain reaction; $R^{2}$ : Degree of correlation; SD: Standard deviation; SPSS: Statistical Package for Social Sciences.}

\section{Acknowledgments \\ The authors thank the support of the Sports Trauma Center of the National Institute of Traumatology and Orthopaedics (INTO), Sports Training Center and National or State Sports Championships for an opportunity to recruit athletes. And the technical assistance of Victor Soares Wainchtock from Laboratório de Pesquisa de Ciências Farmacêuticas - LAPESF (https://lapesfuezo.wixsite.com/ website), Centro Universitário Estadual da Zona Oeste (UEZO) and Research Division of INTO. This study was supported by the Brazilian agency Fundação Carlos Chagas Filho de Amparo à Pesquisa do Estado do Rio de Janeiro - FAPERJ, Brazil. The funding body contributed to the acquisition of research inputs.}

\section{Authors' contributions}

$J A P, L R L, R A G$, and VRAC participated in conception and design of the study. JAP, LRL, RAG, LFAP, CGP, and VRAC collated the data and developed the database. JAP and LRL performed the experiments and statistical analysis. JAP, LRL, $M M, A M V, E B S$, and VRAC analysis and interpretation of data. JAP, LRL, AMV EBS, and VRAC wrote the manuscript. JAMG critical revision of the manuscript for important intellectual content. All authors read and approved the final manuscript.

\section{Funding}

This study was supported by the Brazilian agency Fundação Carlos Chagas Filho de Amparo à Pesquisa do Estado do Rio de Janeiro - FAPERJ and Coordenação de Aperfeiçoamento de Pessoal de Nível Superior - CAPES, Brazil. Funding body contributed to acquisition of research inputs.

\section{Availability of data and materials}

The datasets used and/or analyzed during the current study are available from the corresponding author on reasonable request.

\section{Declarations}

\section{Ethics approval and consent to participate}

This study was approved by the Human Research Ethics Committee of the Instituto Nacional de Traumatologia e Ortopedia, Rio de Janeiro, 
Brazil (protocol number 2.455.630/2017). All participants provided written informed consent. The study was conducted in accordance with the Helsinki Declaration.

\section{Consent for publication}

Not applicable.

\section{Competing interests}

The authors declare that they have no competing interests.

\section{Author details}

${ }^{1}$ Divisão de Ensino e Pesquisa, Instituto Nacional de Traumatologia e Ortopedia (INTO), Avenida Brasil, 500, Rio de Janeiro 20940-070, Brazil. ${ }^{2}$ Laboratório de Pesquisa de Ciências Farmacêuticas, Centro Universitário Estadual da Zona Oeste (UEZO), Rio de Janeiro, Brazil. ${ }^{3}$ Programa de Pós-graduação em Saúde Pública e Meio Ambiente, Escola Nacional de Saúde Pública, Fundação Oswaldo Cruz (Fiocruz), Rio de Janeiro, Brazil. ${ }^{4}$ Centro de Trauma do Esporte, Instituto Nacional de Traumatologia e Ortopedia (INTO), Rio de Janeiro, Brazil. ${ }^{5}$ Centro de Cirurgia do Joelho, Instituto Nacional de Traumatologia e Ortopedia (INTO), Rio de Janeiro, Brazil.

\section{Received: 14 October 2021 Accepted: 10 February 2022}

Published online: 16 February 2022

\section{References}

1. Kim S, Akaike T, Sasagaw T, Atomi Y, Kurosawa H. Gene expression of type I and type III collagen by mechanical stretch in anterior cruciate ligament cells. Cell Struct Funct. 2002;27(3):139-44 [cited 2021 Jul 28] Available from: https://pubmed.ncbi.nlm.nih.gov/12207044/.

2. Hsu S, Liang R, Woo S. Functional tissue engineering of ligament healing. Sports Med Arthrosc Rehabil Ther Technol. 2010;2(1):21 [cited 2021 Jul 28]. Available from: https://pubmed.ncbi.nlm.nih.gov/20492676/.

3. Kiapour A, Murray M. Basic science of anterior cruciate ligament injury and repair. Bone Joint Res. 2014;3(2):20-31 [cited 2021 Jul 28]. Available from: https://pubmed.ncbi.nlm.nih.gov/24497504/.

4. Nguyen D, Ramwadhdoebe T, van der Hart C, Blankevoort L, Tak P, van Dijk C. Intrinsic healing response of the human anterior cruciate ligament: an histological study of reattached ACL remnants. J Orthop Res. 2014;32(2):296-301 [cited 2021 Jul 28]. Available from: https://pubmed. ncbi.nlm.nih.gov/24600702/.

5. Matsumoto H, Suda Y, Otani T, Niki Y, Seedhom B, Fujikawa K. Roles of the anterior cruciate ligament and the medial collateral ligament in preventing valgus instability. J Orthop Sci. 2001;6(1):28-32 [cited 2021 28]. Available from: https://pubmed.ncbi.nlm.nih.gov/11289582/.

6. Duthon V, Barea C, Abrassart S, Fasel J, Fritschy D, Ménétrey J. Anatomy of the anterior cruciate ligament. Knee Surg Sports Traumatol Arthrosc. 2006;14(3):204-13 [cited 2021 Jul 28]. Available from: https://pubmed. ncbi.nlm.nih.gov/16235056/.

7. Vundelinckx B, Herman B, Getgood A, Litchfield R. Surgical Indications and Technique for Anterior Cruciate Ligament Reconstruction Combined with Lateral Extra-articular Tenodesis or Anterolateral Ligament Reconstruction. Clin Sports Med. 2017;36(1):135-53 [cited 2021 Jul 28]. Available from: https://pubmed.ncbi.nlm.nih.gov/27871655/.

8. Hewett T, Di Stasi S, Myer G. Current concepts for injury prevention in athletes after anterior cruciate ligament reconstruction. Am J Sports Med. 2013;41(1):216-24 [cited 2021 Jul 28]. Available from: https://pubmed. ncbi.n/m.nih.gov/23041233/.

9. Pfeifer C, Beattie $P, \ldots$ RS-I journal of, 2018 undefined. Risk factors associated with non-contact anterior cruciate ligament injury: a systematic review. ncbi.nlm.nih.gov [Internet]. [cited 2021 Jul 28]; Available from: https://www.ncbi.nlm.nih.gov/pmc/articles/pmc6088120/

10. Hewett T, Myer G, Ford H, Heidt R, Colosimo A, McLean S, et al. Biomechanical measures of neuromuscular control and valgus loading of the knee predict anterior cruciate ligament injury risk in female athletes: a prospective study. Am J Sports Med. 2005;33(4):492-501 [cited 2021 Jul 28]. Available from: https://pubmed.ncbi.nlm.nih.gov/15722287/.

11. Waldén M, Krosshaug T, Bjørneboe J, Andersen T, Faul O, Hägglund M. Three distinct mechanisms predominate in non-contact anterior cruciate ligament injuries in male professional football players: a systematic video analysis of 39 cases. Br J Sports Med. 2015;49(22):1452-60 [cited 2021 Jul 28]. Available from: https://pubmed.ncbi.nlm.nih.gov/25907183/.

12. Hewett T. Neuromuscular and hormonal factors associated with knee injuries in female athletes. Strategies for intervention. Sports Med. 2000;29(5):313-27 [cited 2021 Jul 28]. Available from: https://pubmed. ncbi.nlm.nih.gov/10840866/.

13. Kaeding C, Léger-St-Jean B, Magnussen R. Epidemiology and Diagnosis of Anterior Cruciate Ligament Injuries. Clin Sports Med. 2017;36(1):1-8 [cited 2021 Jul 28]. Available from: https://pubmed.ncbi.nlm.nih.gov/ 27871652/.

14. Nwachukwu B, Voleti P, Berkanish P, Chang B, Cohn M, Williams R, et al. Return to Play and Patient Satisfaction After ACL Reconstruction: Study with Minimum 2-Year Follow-up. J Bone Joint Surg Am. 2017;99(9):720-5 [cited $2021 \mathrm{Jul}$ 28]. Available from: https://pubmed.ncbi.nlm.nih.gov/ 28463915/.

15. Goes RA, Cossich VRA, França BR, Campos AS, Souza GGA, do Bastos RC, et al. Return to play after anterior cruciate ligament reconstruction. Rev Bras Med do Esporte. 2020;26(6):478-86 [cited 2021 Jul 28]. Available from: http://www.scielo.br/j/rbme/a/fXnqrrFhyBX6pmQ4qYtfMSr/?lang= en.

16. Jia Z, Zhang C, Cao S, Xue C, Liu T, Huang X, et al. Comparison of artificial graft versus autograft in anterior cruciate ligament reconstruction: a meta-analysis. BMC Musculoskelet Disord. 2017;18(1):19 [cited 2021 Jul 28]. Available from: https://pubmed.ncbi.nlm.nih.gov/28724372/.

17. Waldén M, Hägglund M, Magnusson H, Ekstrand J. ACL injuries in men's professional football: a 15-year prospective study on time trends and return-to-play rates reveals only $65 \%$ of players still play at the top level 3 years after ACL rupture. Br J Sports Med. 2016;50(12):744-50 [cited 2021 Jul 28]. Available from: https://pubmed.ncbi.nlm.nih.gov/27034129/.

18. de Loës M, Dahlstedt L, Thomée R. A 7-year study on risks and costs of knee injuries in male and female youth participants in 12 sports. Scand J Med Sci Sports. 2000;10(2):90-7 [cited 2021 Jul 28]. Available from: https://pubmed.ncbi.nlm.nih.gov/10755279/.

19. Smith H, Vacek P, Johnson R, Slauterbeck J, Hashemi J, Shultz S, et al. Risk factors for anterior cruciate ligament injury: a review of the literature part 1: neuromuscular and anatomic risk. Sports Health. 2012;4(1):69-78 [cited $2021 \mathrm{Jul}$ 28]. Available from: https://pubmed.ncbi.nlm.nih.gov/ 23016072/.

20. Stępień-Słodkowska M, Ficek K, Kaczmarczyk M, Maciejewska A, Sawczuk $M$, Eider J, et al. Influence of biological factors on injuries occurrence in the Polish population. Ann Agric Environ Med. 2016;23(2):315-8 [cited $2021 \mathrm{Jul}$ 28]. Available from: https://pubmed.ncbi.nlm.nih.gov/27294 639/.

21. Shultz S, Schmitz R, Benjaminse A, Collins M, Ford K, Kulas A. ACL Research Retreat VII: An Update on Anterior Cruciate Ligament Injury Risk Factor Identification, Screening, and Prevention. J Athl Train [Internet]. 2015;50(10):1076-1093. [cited 2021 Jul 28]. Available from: https://pubmed.ncbi.nlm.nih.gov/26340613/

22. Magnusson K, Turkiewicz A, Hughes V, Frobell R, Englund M. High genetic contribution to anterior cruciate ligament rupture: Heritability $\sim 69 . \mathrm{Br} J$ Sports Med. 2020;55(7):385-9 [cited 2021 Jul 28]. Available from: https:// pubmed.ncbi.nlm.nih.gov/33288618/.

23. Khoschnau S, Melhus $\mathrm{H}$, Jacobson A, Rahme H, Bengtsson H, Ribom E, et al. Type I collagen alpha1 Sp1 polymorphism and the risk of cruciate ligament ruptures or shoulder dislocations. Am J Sports Med. 2008;36(12):2432-6 [cited 2021 Jul 28]. Available from: https://pubmed. ncbi.nlm.nih.gov/18669982/.

24. Posthumus M, September A, Keegan M, O'Cuinneagain D, Van der Merwe W, Schwellnus M, et al. Genetic risk factors for anterior cruciate ligament ruptures: COL1A1 gene variant. Br J Sports Med. 2009;43(5):352-6 [cited 2021 Jul 28]. Available from: https://pubmed.ncbi.nlm.nih.gov/19193 $663 /$

25. Ficek K, Cieszczyk P, Kaczmarczyk M, Maciejewska-Karłowska A, Sawczuk $\mathrm{M}$, Cholewinski J, et al. Gene variants within the COL1A1 gene are associated with reduced anterior cruciate ligament injury in professional soccer players. J Sci Med Sport. 2013;16(5):396-400 [cited 2021 Jul 28]. Available from: https://pubmed.ncbi.nlm.nih.gov/23168334/.

26. O'Connell K, Knight H, Ficek K, Leonska-Duniec A, Maciejewska-Karlowska A, Sawczuk M, et al. Interactions between collagen gene variants and risk of anterior cruciate ligament rupture. Eur J Sport Sci. 15(4):341-50 2015 
May 19 [cited 2021 Jul 28]. Available from: https://pubmed.ncbi.nlm.nih. gov/25073002/.

27. Wang C, Li H, Chen K, Wu B, Liu H. Association of polymorphisms rs 1800012 in COL1A1 with sports-related tendon and ligament injuries: a meta-analysis. Oncotarget. 2017;8(16):27627-34 [cited 2021 Jul 28]. Available from: https://pubmed.ncbi.nlm.nih.gov/28206959/.

28. Zhao D, Zhang Q, Lu Q, Hong C, Luo T, Duan Q, et al. Correlations Between the Genetic Variations in the COL1A1, COL5A1, COL12A1, and $\beta$-fibrinogen Genes and Anterior Cruciate Ligament Injury in Chinese Patients a. J Athl Train. 2020;55(5):515-21 [cited 2021 Jul 28]. Available from: https://pubmed.ncbi.nlm.nih.gov/32239963/.

29. Georgiev G, Kotov G, lliev A, Slavchev S, Ovtscharoff W, Landzhov B. A comparative study of the epiligament of the medial collateral and the anterior cruciate ligament in the human knee. Immunohistochemical analysis of collagen type I and V and procollagen type III. Ann Anat. 2019;224:88-96 [cited 2021 Jul 28]. Available from: https://pubmed.ncbi. nIm.nih.gov/31022516/.

30. Frank C. Ligament structure, physiology and function. J Musculoskelet Neuronal Interact. 2004;4(2):199-201 [cited 2021 Jul 28]. Available from: https://pubmed.ncbi.nlm.nih.gov/15615126/.

31. Gajko-Galicka A. Mutations in type I collagen genes resulting in osteogenesis imperfecta in humans. Acta Biochim Pol. 2002;49(]):433-441. [cited 2021 Jul 28]. Available from: https://pubmed.ncbi.nlm.nih.gov/ 12362985/

32. Ponticos M, Abraham D, Alexakis C, Lu Q, Black C, Partridge T, et al. Col1a2 enhancer regulates collagen activity during development and in adult tissue repair. Matrix Biol. 2004;22(8):619-28 [cited 2021 Jul 28]. Available from: https://pubmed.ncbi.nlm.nih.gov/15062855/.

33. Forlino A, Cabral W, Barnes A, Marini J. New perspectives on osteogenesis imperfecta. Nat Rev Endocrinol. 2011;7(9):540-57 [cited 2021 Jul 28]. Available from: https://pubmed.ncbi.nlm.nih.gov/21670757/.

34. Garcia-Giralt N, Nogués X, Enjuanes A, Puig J, Mellibovsky L, Bay-Jensen $A$, et al. Two new single-nucleotide polymorphisms in the COL1A1 upstream regulatory region and their relationship to bone mineral density. J Bone Miner Res. 2002;17(3):384-93 [cited 2021 Jul 28]. Available from: https://pubmed.ncbi.nlm.nih.gov/11874231/.

35. Goes R, Lopes L, Cossich V, de Miranda V, Coelho O, do Carmo Bastos R, et al. Musculoskeletal injuries in athletes from five modalities: a crosssectional study. BMC Musculoskelet Disord. 2020;21(1):24 [cited 2021 Jul 28]. Available from: https://pubmed.ncbi.nlm.nih.gov/32093651/.

36. Lopes L, de Miranda V, Guimarães J, de Araujo SG, Wainchtock V, Grangeiro Neto J, et al. Association of TNF-a -308G > A polymorphism with susceptibility to tendinopathy in athletes: a case-control study. BMC Sport Sci Med Rehabil. 2021;13(1):1 [cited 2021 Jul 28]. Available from: https://pubmed.ncbi.nlm.nih.gov/33985554/.

37. Perini J, Cardoso J, Berardo P, Vianna-Jorge R, Nasciutti L, Bellodi-Privato $M$, et al. Role of vascular endothelial growth factor polymorphisms $(-2578 \mathrm{C}>\mathrm{A},-460 \mathrm{~T}>\mathrm{C},-1154 \mathrm{G}>\mathrm{A},+405 \mathrm{G}>\mathrm{C}$ and $+936 \mathrm{C}>\mathrm{T})$ in endometriosis: a case-control study with Brazilians. BMC Womens Health. 2014;14(1):26 [cited 2021 Jul 28]. Available from: https://pubmed.ncbi. nIm.nih.gov/25255852/.

38. Sayampanathan A, Howe B, Bin Abd Razak H, Chi C, Tan A. Epidemiology of surgically managed anterior cruciate ligament ruptures in a sports surgery practice. J Orthop Surg (Hong Kong). 2017;25(1):1 [cited 2021 Jul 28]. Available from: https://pubmed.ncbi.nlm.nih.gov/28142351/.

39. Larwa J, Stoy C, Chafetz R, Boniello M, Franklin C. Stiff Landings, Core Stability, and Dynamic Knee Valgus: A Systematic Review on Documented Anterior Cruciate Ligament Ruptures in Male and Female Athletes. Int J Environ Res Public Health. 2021;18(7):1 [cited 2021 Jul 28]. Available from: https://pubmed.ncbi.nlm.nih.gov/33917488/.

40. Alentorn-Geli E, Myer G, Silvers H, Samitier G, Romero D, Lázaro-Haro C, et al. Prevention of non-contact anterior cruciate ligament injuries in soccer players. Part 1: Mechanisms of injury and underlying risk factors. Knee Surg Sports Traumatol Arthrosc. 2009;17(7):705-29 [cited 2021 Jul 28]. Available from: https://pubmed.ncbi.nlm.nih.gov/19452139/.

41. Bahr R, Krosshaug T. Understanding injury mechanisms: a key component of preventing injuries in sport. Br J Sports Med. 2005;39(6):324-9 [cited 2021 Jul 28]. Available from: https://pubmed.ncbi.nlm.nih.gov/15911 $600 \%$

42. Joseph A, Collins C, Henke N, Yard E, Fields S, Comstock R. A multisport epidemiologic comparison of anterior cruciate ligament injuries in high school athletics. J Athl Train. 2013;48(6):810-7 [cited 2021 Jul 28]. Available from: https://pubmed.ncbi.nlm.nih.gov/24143905/.

43. Beynnon B, Vacek P, Newell M, Tourville T, Smith H, Shultz S, et al. The Effects of Level of Competition, Sport, and Sex on the Incidence of FirstTime Noncontact Anterior Cruciate Ligament Injury. Am J Sports Med. 2014;42(8):1806-12 [cited 2021 Jul 28]. Available from: https://pubmed. ncbi.nlm.nih.gov/25016012/.

44. Montalvo A, Schneider D, Yut L, Webster K, Beynnon B, Kocher M, et al. "What's my risk of sustaining an ACL injury while playing sports?" A systematic review with meta-analysis. Br J Sports Med. 2019;53(16):1003-12 [cited 2021 Jul 28]. Available from: https://pubmed.ncbi.nlm.nih.gov/ 29514822/.

45. Nitta C, Baldan C, Costa L, Cohen M, Pagura J, Arliani G. Epidemiology of anterior cruciate ligament injury in soccer players in the brazilian championship. Acta Ortop Bras. 2021;29(1):45-8 [cited 2021 Jul 28]. Available from: https://pubmed.ncbi.nlm.nih.gov/33795969/.

46. Yoneyama T, Kasuya H, Onda H, Akagawa H, Hashiguchi K, Nakajima T, et al. Collagen type I alpha2 (COL1A2) is the susceptible gene for intracranial aneurysms. Stroke. 2004;35(2):443-8 [cited 2021 Jul 28]. Available from: https://pubmed.ncbi.nlm.nih.gov/14739420/.

47. Lindahl K, Rubin C, Brändström H, Karlsson M, Holmberg A, Ohlsson $C$, et al. Heterozygosity for a coding SNP in COL1A2 confers a lower $\mathrm{BMD}$ and an increased stroke risk. Biochem Biophys Res Commun. 2009;384(4):501-5 [cited $2021 \mathrm{Jul}$ 28]. Available from: https://pubmed. ncbi.nlm.nih.gov/19426706/.

48. Marieswaran M, Jain I, Garg B, Sharma V, Kalyanasundaram D. A review on biomechanics of anterior cruciate ligament and materials for reconstruction. Appl bionics Biomech. 2018;2018:4657824.

49. Sivertsen E, Haug K, Kristianslund E, Trøseid A, Parkkari J, Lehtimäki T, et al No Association Between Risk of Anterior Cruciate Ligament Rupture and Selected Candidate Collagen Gene Variants in Female Elite Athletes From High-Risk Team Sports. Am J Sports Med. 2019;47(1):52-8 [cited 2021 Jul 28]. Available from: https://pubmed.ncbi.nlm.nih.gov/30485117/.

50. Kaynak M, Nijman F, van Meurs J, Reijman M, Meuffels D. Genetic Variants and Anterior Cruciate Ligament Rupture: A Systematic Review. Sports Med. 2017;47(8):1637-50 [cited 2021 Jul 28]. Available from: https:// pubmed.ncbi.nlm.nih.gov/28102489/.

\section{Publisher's Note}

Springer Nature remains neutral with regard to jurisdictional claims in published maps and institutional affiliations.

Ready to submit your research? Choose BMC and benefit from

- fast, convenient online submission

- thorough peer review by experienced researchers in your field

- rapid publication on acceptance

- support for research data, including large and complex data types

- gold Open Access which fosters wider collaboration and increased citations

- maximum visibility for your research: over $100 \mathrm{M}$ website views per year

At BMC, research is always in progress.

Learn more biomedcentral.com/submissions 